\title{
Smoking cessation initiated during hospital stay for patients with coronary artery disease: a randomized controlled trial
}

\author{
Patricia M. Smith PhD, Ellen Burgess MD
}

$\infty \quad$ See related commentary by Rigotti, page 1283

\section{ABSTRACT}

Background: Programs for smoking cessation for cardiac patients are underused in Canada. We examined the efficacy of an intervention for smoking cessation for patients admitted to hospital for coronary artery bypass graft (CABG) or because of acute myocardial infarction (MI).

Methods: Nurses randomly assigned 276 sequential patients admitted because of acute MI or for CABG who met the inclusion criteria. Participants received an intensive or minimal smoking-cessation intervention. The minimal intervention included advice from physicians and nurses and 2 pamphlets. The intensive intervention included the minimal intervention plus 60 minutes of bedside counselling, take-home materials and 7 nurse-initiated counselling calls for 2 months after discharge. The outcomes were point prevalence of abstinence at 3, 6 and 12 months after discharge.

Results: The 12-month self-reported rate of abstinence was $62 \%$ among patients in the intensive group and $46 \%$ among those in the minimal group (odds ratio [OR] 2.0, $95 \%$ confidence interval $[\mathrm{Cl}] 1.2-3.1)$. Abstinence was confirmed for $54 \%$ of patients in the intensive group and $35 \%$ in the minimal group (OR 2.0, 95\% Cl 1.3-3.6). Abstinence was significantly lower among those who used pharmacotherapy than among those who did not $(p<0.001)$. Continuous 12 -month abstinence was $57 \%$ in the intensive group and $39 \%$ in the minimal group $(p<0.01)$. It was significantly higher among patients admitted for CABG than among those admitted because of acute $\mathrm{MI}(p<0.05)$.

Interpretation: Providing intensive programs for smoking cessation for patients admitted for CABG or because of acute $\mathrm{MI}$ could have a major impact on health and health care costs.

Une version française de ce résumé est disponible à l'adresse www.cmaj.ca/cgi/content/full/180/13/1297/DC1

CMAJ 2009;180(13):1297-1303

I nterventions for smoking cessation are underused in cardiac units in Canada, ${ }^{1}$ even though coronary artery disease accounts for a large proportion of hospital admissions among adults aged 45 or more years . ${ }^{2}$ Compared with the use of other secondary prevention and management measures (e.g., statins, acetylsalicylic acid, $\beta$-blockers and angiotensin-converting-enzyme inhibitors), the use of smoking-cessation measures among those with coronary artery disease results in greater reductions in mortality risk ${ }^{1,3,4}$ and greater cost-effectiveness. ${ }^{5}$ Risk reductions in this group include a $32 \%$ decrease in nonfatal reinfarction, $36 \%$ decrease in mortality, ${ }^{3} 300 \%$ reduced risk for repeat coronary artery bypass graft (CABG) ${ }^{6}$ and a decreased risk for restenosis after percutaneous translumial coronary angioplasty from $55 \%$ to $38 \%$.

In this study, we used an intensive intervention, which is the gold standard for smoking cessation among inpatients. When tested in the United States, this intervention resulted in the highest rates of 1-year confirmed cessation reported in the literature. ${ }^{8}$ The intervention involves 45-60 minutes of bedside education and counselling during hospital stay followed by 7 nurse-initiated telephone counselling sessions after discharge. ${ }^{9}$ US trials have reported 1-year confirmed cessation rates of $61 \%$ for this intensive intervention compared to $32 \%$ for a brief intervention when tested as a stand-alone program. ${ }^{10}$ When tested as part of a rehabilitation program for multiple cardiac risk factors, the cessation rates were $70 \%$ and 53\%, respectively. ${ }^{11}$ Despite the success of this approach among cardiac patients, interventions for smoking cessation in inpatients have not been widely adopted in Canada.

In this randomized clinical trial, we investigated the efficacy of a minimal intervention and an intensive intervention for smoking cessation among patients admitted to hospital because of acute myocardial infarction or for CABG.

\section{Methods}

\section{Setting and participants}

The setting was 4 cardiac units in a large urban hospital in western Canada. We considered eligible patients to be those who were 18 years of age or older, used tobacco in the month before admission, had a minimum projected hospital stay of 36 hours (to allow time for the intervention), were willing to be randomly assigned to an intervention and had telephone access to receive counselling after discharge. We excluded patients who were pregnant, involved in a concurrent trial for tobacco cessation, medically unstable (as determined by a physician), lived in an institution without telephone access,

From the Human Science Division, Northern Ontario School of Medicine (Smith); and the Department of Medicine (Burgess), University of Calgary, Calgary, Alta. 
could not speak English or had trouble communicating, had a history of substance abuse or psychiatric disorders, or for whom the patient's physicians refused to allow participation.

The Conjoint Health Research Ethics board of the University of Calgary provided ethics approval for this randomized clinical trial.

\section{Procedure}

Over a 15-month period beginning in December 1999, the research nurse asked all patients admitted to each of the 4 cardiac units if they had used tobacco in the month before admission. She reviewed the medical charts of smokers for eligibility, approached medically stable patients at the bedside, described the study, obtained informed consent and collected baseline data. She opened the randomization envelope and informed the patients of intervention assignment (intensive or minimal). We developed the randomization code using a computer random-number generator to select random permuted blocks of 10. Randomization was stratified by acute $\mathrm{MI}$ and $\mathrm{CABG}$ to ensure equal numbers in each intervention group.

\section{Minimal intervention}

The research nurse advised patients to quit smoking by personalizing the message to each patient's medical conditions. The nurse reviewed 2 pamphlets (how to quit and where to find help quitting) with the patient, and she put a note in each patient's chart to ask the attending physician to deliver a scripted nonsmoking message ${ }^{12}$ at the bedside during the patient's hospital stay. Pharmacotherapy was not part of the study. However, pharmacotherapy was introduced as an aid to cessation and was available through the hospital formulary during the patient's hospital stay if the patient requested it and a physician ordered it. The research nurse explained how to use the medications to patients who were interested.

\section{Intensive intervention}

Patients in this group received the minimal intervention plus 45-60 minutes of bedside education and counselling, takehome materials (video, workbook, audiotape) and 7 telephone counselling sessions initiated by the research nurse $(2,7,14$, 21, 30, 45 and 60 days after discharge). Education covered the patient's personalized risks associated with smoking and the benefits of quitting, as well as withdrawal, weight gain and the benefits of making the home smoke-free. Counselling was based on Marlatt and Gordon's relapse prevention model. ${ }^{13}$ Patients rated their confidence to remain smoke-free in 14 high-risk situations, ${ }^{14}$ and they developed behavioural, cognitive and social support strategies to remain smoke-free in situations for which they had less than $70 \%$ confidence. Telephone counselling, which was designed to last 5-10 minutes per call, ${ }^{15}$ focused on the prevention of relapse (developing cognitive, behavioural and social support strategies for situations identified as high risk for relapse).

\section{Follow-up after discharge}

A research assistant who had no prior contact with the participants called each participant at 3,6 and 12 months after dis- charge to assess the participant's use of tobacco in the previous 7 days. The assistant was blinded to the intervention assignment by not having any information about the patients, except for their name, scheduled callback date and telephone number (the intervention was not known). During the 12-month follow-up call, the research assistant asked all patients who reported not using tobacco to provide the name and contact number of a family member or friend to provide proxy corroboration of their tobacco status. The assistant then called the friend or family member and asked if the patient had smoked or used tobacco in the last 7 days.

\section{Measures}

We collected baseline sociodemographic data, including age, education, employment status, marital status, ethnic background, sex, weekly alcohol consumption, whether patients lived alone or with a smoker, social support to quit tobacco, and the degree of restrictions on tobacco use at home and work. Medical information included history of acute MI, CABG, percutaneous translumial coronary angioplasty, peripheral vascular disease, chronic obstructive pulmonary disease, diabetes, number of weeks of stable angina, hospital admissions in the previous year, length of the current hospital stay, and discharge diagnosis based on the International Classification of Disease (ninth revision [ICD-9]) codes. ${ }^{16}$

We collected information on the history of tobacco use, including the amount and number of years smoked, number of quit attempts, tobacco addictions (5-item modified Fagerstrom Tolerance Questionnaire ${ }^{17}$ ), and previous use of pharmacotherapy, as well as in-hospital withdrawal and difficulty quitting while in hospital. Psychosocial information included single-item screens of the patient's confidence to quit ( $0 \%-100 \%$ confidence), intention to quit (1-7, with 7 being full intention), depressed mood (0 [not at all] to 8 [very severely depressed]), and beliefs about whether they could avoid health problems by quitting (1 [very likely] to 4 [very unlikely]), whether tobacco was harming their health, and whether it was worth quitting after 20 years of using tobacco (1 [strongly agree] to [4 strongly disagree $\left.]^{18}\right)$.

\section{Primary outcome}

Our primary outcome was smoking status at 3,6 and 12 months after discharge. We measured smoking status using the National Heart, Lung and Blood Institute' ${ }^{19}$ consensusconference definition of self-reported 7-day point prevalence of abstinence (not even a puff for a minimum of 7 consecutive days before the assessment) and long-term (continuous) abstinence, which was measured by self-reported 7-day pointprevalence at 3, 6 and 12 months.

Although self-reported tobacco status is a valid measure, ${ }^{20,21}$ we used proxy confirmation as a conservative fidelity check of abstinence at 12 months. Proxy corroboration results in similar abstinence rates to carbon monoxide confirmation of tobacco rates. ${ }^{22,23}$ In this trial, it was more feasible to use a proxy measure than to ask patients to return to hospital to provide a sample for biochemical confirmation because patients resided not only in the hospital community but also in outlying rural areas. 


\section{Data analyses}

We assumed that the 12-month confirmed abstinence would be $30 \%$ in the minimal intervention group (based on the Stanford study ${ }^{10}$ ); thus, 136 participants per group were needed to give an $80 \%$ probability of detecting a clinically significant $10 \%$ increase in abstinence rates with the intensive intervention $(\alpha=0.05,1$ tailed).

We compared the baseline characteristics between the intervention groups using $\chi^{2}$ tests for categorical and dichotomous variables and $t$ tests for continuous variables. Although statistical testing for baseline differences is discouraged by some ${ }^{24}$ others maintain that baseline differences can occur between treatment groups, even with adequate randomization and allocation concealment. ${ }^{25}$ Thus, the differences should be checked to ensure that the results of this trial and future systematic reviews and meta-analyses that include this trial are not biased. ${ }^{26}$
For outcomes related to tobacco status, we used hierarchical logistic regression to test for the main effects of the intervention (intensive v. minimal) and the reason for admission to hospital (CABG v. acute MI) and the interaction between the intervention and the reason for admission. Odds ratios (ORs) with $95 \%$ confidence intervals (CIs), derived from the last statistically significant step in the logistic analyses, were used to determine the significance of the main effects and the interaction. We excluded from the anslyses participants who had died. Those who had dropped out or for whom cessation data were not available were considered smokers for the time points at which their data were missing.

Our secondary analyses included a hierarchical logistic regression analysis to test for the effects of the intervention, pharmacotherapy and the interaction between the intervention and pharmacotherapy on 12-month abstinence. We also performed logistic regression analysis to determine predictors of 12-month

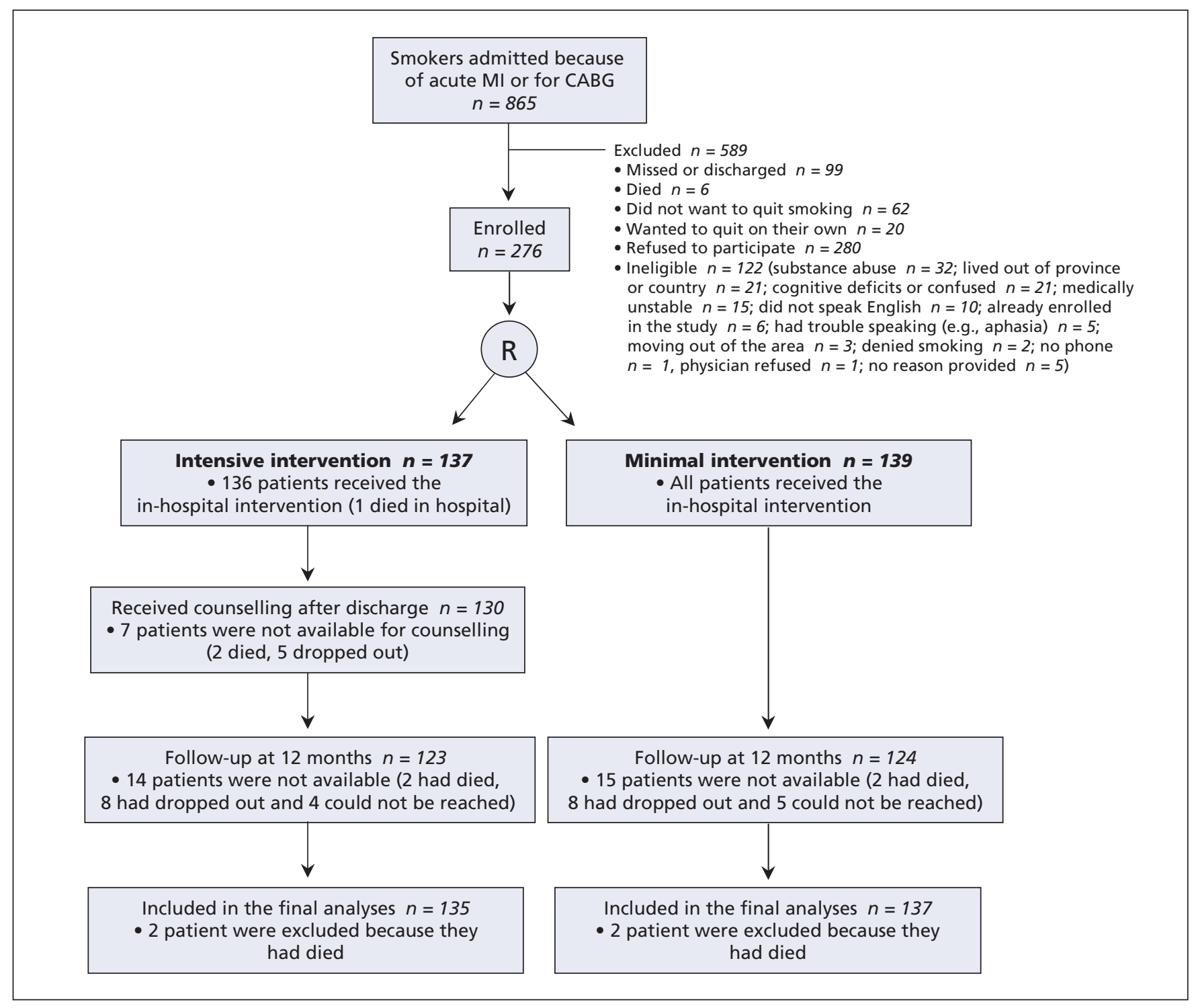

Figure 1: Patient enrollment, allocation, intervention completion and follow-up. Note: $\mathrm{CABG}=$ coronary artery bypass graft, $\mathrm{MI}=\mathrm{my}-$ ocardial infarction. 
cessation, while adhering to conventions to prevent over-fitting the prediction model to the sample. ${ }^{27}$ The predictors included in the analysis were age, sex, education, admission for CABG or acute MI, history of acute MI, addiction, confidence to quit tobacco, restrictions on indoor tobacco use at home, depression, use of alcohol, and whether the patient had quit tobacco for at least 1 week in the year before hospital admission.

\section{Results}

\section{Patient enrollment and flow through the trial}

Recruitment began in December 1999, and follow-up ended in March 2003. Of the 10336 admissions to the 4 cardiac units, $19 \%$ were because of acute MI $(n=1921)$ and $14 \%$ were for CABG $(n=1425)$. Of the patients with acute MI, $34 \%(n=654)$ were smokers, and $15 \%$ of the patients admitted for CABG $(n=211)$ were smokers. The overall smoking prevalence rate was $26 \%(865 / 3346)$. Of the patients admitted because of acute $\mathrm{MI}$ or for CABG who smoked, $32 \%$ were enrolled (276/865) in the study (Figure 1).

\begin{tabular}{|c|c|c|c|c|}
\hline \multirow[b]{2}{*}{ Characteristic } & \multicolumn{2}{|c|}{ Intensive intervention } & \multicolumn{2}{|c|}{ Minimal intervention } \\
\hline & $\mathrm{n} / \mathrm{N}^{*}$ & $\begin{array}{l}\% \text { of } \\
\text { patients* }\end{array}$ & $\mathrm{n} / \mathrm{N}^{*}$ & $\begin{array}{c}\% \text { of } \\
\text { patients* }\end{array}$ \\
\hline $\begin{array}{l}\text { Hospital stay, d, mean (SD), } \\
\text { range }\end{array}$ & $9(6)$ & $1-36$ & $9(7)$ & $2-59$ \\
\hline \multicolumn{5}{|l|}{ Discharge diagnosist } \\
\hline CABG $\ddagger$ & $27 / 137$ & 20 & $31 / 139$ & 22 \\
\hline CABG and MI§ & $16 / 137$ & 12 & $15 / 139$ & 11 \\
\hline MIף & $41 / 137$ & 30 & $41 / 139$ & 30 \\
\hline $\mathrm{MI}$ and PTCA** & $49 / 137$ & 36 & $47 / 139$ & 34 \\
\hline \multicolumn{5}{|l|}{ Other } \\
\hline PTCA†t & $2 / 137$ & 2 & $2 / 139$ & 1 \\
\hline Coronary artery disease $\ddagger$ & $2 / 137$ & 2 & $3 / 139$ & 2 \\
\hline \multicolumn{5}{|l|}{ Medical history } \\
\hline Previous MI & $22 / 130$ & 17 & 27/137 & 20 \\
\hline Previous CABG & $5 / 134$ & 4 & $3 / 137$ & 2 \\
\hline Previous PTCA & $12 / 133$ & 9 & $18 / 137$ & 13 \\
\hline $\begin{array}{l}\text { Chronic obstructive pulmonary } \\
\text { disease }\end{array}$ & $2 / 133$ & 2 & $5 / 129$ & 4 \\
\hline Peripheral vascular disease & $4 / 132$ & 3 & $8 / 136$ & 6 \\
\hline $\begin{array}{l}\text { Unstable angina in the previous } \\
\text { week }\end{array}$ & $113 / 130$ & 87 & $104 / 128$ & 81 \\
\hline Diabetes & $23 / 131$ & 18 & $24 / 138$ & 17 \\
\hline
\end{tabular}

Note: $\mathrm{CABG}=$ coronary artery bypass graft, $\mathrm{MI}=$ myocardial infarction,

PTCA = percutaneous transluminal coronary angioplasty, SD = standard deviation.

*Unless otherwise stated.

tBased on ICD-9 codes. $^{15}$

†ICD-9 codes $36.10-36.14$

§ICD-9 codes 36.10-36.14 (CABG) and ICD-9 codes 410.0-410.9 (MI).

ๆICD-9 codes 410.0-410.9.

**ICD-9 codes 410.0-410.9 (MI) and ICD-9 code 36 (PTCA).

†+ICD-9 code 36.

$\neq I C D-9$ codes $414.0-414.9$.
All of the patients that were randomly assigned to the minimal intervention and all but 1 of the patients assigned to the intensive intervention received the in-hospital intervention. Of the patients in the intensive intervention, 95\% (130/137) received the postdischarge intervention. On average, $93 \%$ of patients were available per call, $5 \%$ were not reached, and $2 \%$ were not called because the research nurse was absent, on vacation or missed a call. Patients received an average of 6.56 (standard deviation 0.8 ) calls. At the end of the 12-month period, $4(1 \%)$ patients had died, $16(6 \%)$ had dropped out of the study and $9(3 \%)$ were not reached for the final follow-up (i.e., phone line busy, no answer, answering machine, messages not returned).

\section{Participant characteristics}

Stratified randomization resulted in equal numbers of CABG and acute MI patients assigned to each intervention group (Table 1). Nine patients did not have an ICD-9 discharge diagnosis code of CABG or acute MI, although they had been admitted for acute MI. There were no significant differences between the groups for medical history (Table 1) or baseline variables (Table 2).

\section{Self-reported abstinence at 3, 6 and 12 months}

More patients in the intensive intervention than in the minimal intervention reported not smoking at 3 months $(p=0.009)$, 6 months $(p=0.003)$ and 12 months $(p=0.007)$ (Table 3$)$. The odds of quitting were 2 times greater for patients who received the intensive intervention compared with the minimal intervention at 3, 6 and 12 months (Table 3). The reason for admission to hospital (CABG v. acute $\mathrm{MI})$ or the interaction between the intervention and reason for admission did not contribute significantly to the variance in cessation at any follow-up time.

\section{Confirmation of self-reported abstinence}

Of the patients who reported not smoking after 12 months, 16\% (23/147) did not provide proxy information to allow us to confirm their smoking status. These patients were considered smokers in this analysis. Of the patients who provided proxy information (84\%, 124/147), 3 were reported by a friend or family member to have smoked during the past 7 day ( 2 in the minimal intervention group, 1 in the intensive intervention group). These 3 patients were considered smokers in this analysis.

More patients in the intensive intervention than in the minimal intervention were confirmed nonsmokers at 12 
months $(p=0.002)$ (Table 3). There was no significant effect of reason for admission to hospital (CABG v. acute MI) or significant interaction between the intervention and the reason for admission.

\section{Continuous abstinence at 3, 6 and 12 months}

The intervention $(p=0.004)$ and the reason for hospital admission (CABG v. acute MI) $(p=0.04)$ were significant predictors of continuous abstinence. The interaction between the intervention and having CABG or acute MI was not significant $(p=0.24)$. Patients who received the intensive intervention had significantly higher rates of continuous abstinence than those who received the minimal intervention (57\% [77/135] v. $39 \%$ [54/137]; OR 2.1, 95\% CI 1.3-3.4, $p=0.003$ ). Patients admitted to hospital for CABG had significantly higher rates of continuous abstinence than those admitted because of acute MI (57\% [50/88] v. 44\% [81/184]; OR 1.7, 95\%CI 1.0-2.9, $p=0.038$; Table 4).

\section{Pharmacotherapy}

Although pharmacotherapy was not part of either intervention, it was used by $34 \%$ of patients in both groups (minimal intervention: 40/118 patients; intensive intervention: 40/116 patients [data were missing for 19 patients in each group]). Both the intervention and the use of pharmacotherapy were predictors of abstinence $(p=0.001)$; the interaction between the intervention and the use of pharmacotherapy was not $(p=0.26)$. Patients who received the intensive intervention had significantly higher odds of being abstinent at 12 months than those who received the minimal intervention (69\% [80/116] v. 48\% [56/118], OR 2.7, 95\% CI 1.5-4.8). In both interventions, patients who used pharmacotherapy had significantly lower odds of being abstinent at 12 months (39\% [31/80] v. 68\% [105/154], OR 0.3, 95\% CI 0.2-0.5; Table 4).

\section{Predictors of 12-month abstinence}

Twenty-four patients were missing data for at least 1 of the predictor variables and were excluded from the analyses, leaving a sample size of 248 patients. Significant predictors of the point-prevalence of abstinence at 12 months included receiving the intensive (v. minimal) intervention (OR 2.12, 95\% CI 1.2-3.7), having no history (v. having a history) of acute MI before the current admission (OR 2.94, 95\% CI 1.3-6.5), having a postsecondary education (v. having a high school education or less) (OR 2.34, 95\% CI 1.3-4.1) and having at least some smoking restrictions at home (v. no restrictions) (OR 1.96, 95\% CI 1.1-3.5).

\section{Interpretation}

More patients in the intensive intervention than in the minimal intervention were abstinent at 1 year (absolute increase of

Table 2: Demographic characteristics and smoking history of patients admitted to hospital because of myocardial infarction or for coronary artery bypass grafting who received a minimal or intensive intervention for smoking cessation

\begin{tabular}{|c|c|c|c|c|}
\hline Characteristic & \multicolumn{2}{|c|}{ Intensive intervention } & \multicolumn{2}{|c|}{ Minimal intervention } \\
\hline Age, yr, mean (SD), range & $54(10)$ & $35-80$ & $54(10)$ & 27-79 \\
\hline Male & $113 / 137$ & 82 & $115 / 139$ & 83 \\
\hline White & $129 / 137$ & 94 & $128 / 138$ & 93 \\
\hline Married or common law & $107 / 137$ & 78 & $105 / 139$ & 76 \\
\hline Employed & $103 / 137$ & 75 & 99/139 & 71 \\
\hline Live alone & $33 / 137$ & 24 & $32 / 139$ & 23 \\
\hline Severity of tobacco addiction, $\uparrow$ mean (SD), range & $14.1(4.0)$ & $5-24$ & $14.6(4.5)$ & $7-25$ \\
\hline No. of cigarettes per day, mean (SD), mode; range & $22(11)$ & $25 ; 3-62$ & $21(12)$ & $25 ; 1-60$ \\
\hline No. of years smoked, mean (SD), range & $36(10)$ & $10-60$ & $36(12)$ & $10-68$ \\
\hline Intention to quit, $\S$ mean (SD), range & $6.8(0.6)$ & $3-7$ & $6.8(0.6)$ & $4-7$ \\
\hline Depression, mean (SD), range** & $0.94(2.0)$ & $0-8$ & $1.04(2.0)$ & $0-8$ \\
\hline No. of drinks per week, $\dagger+$ mean (SD), range & $2(4)$ & $0-20$ & $3(4)$ & $0-21$ \\
\hline At least some smoking restrictions at home & $77 / 137$ & 56 & $76 / 139$ & 55 \\
\hline
\end{tabular}

Note: $\mathrm{SD}=$ standard deviation.

*Unless stated otherwise.

tModified Fagerstrom Tolerance Index ${ }^{16}$ scored from 5 to 25 (low to severe addiction)

¥Measured on a 1-item screen, $0 \%$ (no confidence) to $100 \%$ (completely confident).

$\S$ Measured on a 7-point 1-item screen, 1 (no intention to quit) to 7 (full intention).

$* *$ Measured on a 1-item screen, 0 (not at all depressed) to 8 (severely depressed).

t+Presented only for those who reported drinking (intensive intervention $n=96$, minimal intervention $n=96$ ). 
19\%). The odds of quitting smoking were 2 times greater for those in the intensive intervention. The unique contributions of this study include significantly higher rates of continuous abstinence for patients admitted to hospital for CABG than for acute MI, significantly lower rates of abstinence among patients who used pharmacotherapy regardless of the intervention group (which is a finding consistent with general hospital patients $)^{28}$ and real-time tracking of the prevalence of tobacco use among patients admitted for acute MI or CABG. The prevalence of tobacco use was higher for patients with acute MI (34\%) than the provincial average of smoking prevalence $(22 \%-24 \%)$, ${ }^{29}$ which is an important consideration for case-load estimation. In addition to receiving the intensive intervention, the absence of a previous acute MI and having a postsecondary education and at least some restrictions on smoking at home contributed to successful long-term cessation of tobacco use.

Table 3: Point prevalence and confirmed rates of abstinence after receipt of a minimal or intensive intervention for smoking cessation

\begin{tabular}{|c|c|c|c|c|c|c|}
\hline \multirow[b]{2}{*}{ Abstinence } & \multicolumn{2}{|c|}{ Intervention; no. (\%) of patients } & \multirow[b]{2}{*}{$\begin{array}{c}\text { Difference, } \\
\%\end{array}$} & \multirow[b]{2}{*}{$p$ value } & \multirow[b]{2}{*}{ OR } & \multirow[b]{2}{*}{$(95 \% \mathrm{Cl})$} \\
\hline & $\begin{array}{c}\text { Intensive } \\
n=135\end{array}$ & $\begin{array}{c}\text { Minimal } \\
n=137\end{array}$ & & & & \\
\hline \multicolumn{7}{|c|}{ Self-reported } \\
\hline 3 months & $102(76)$ & $83(61)$ & 15 & 0.009 & 2.0 & $(1.2-3.4)$ \\
\hline 6 months & $90(67)$ & 67 (49) & 18 & 0.003 & 2.0 & $(1.3-3.4)$ \\
\hline 12 months & $84(62)$ & $63(46)$ & 16 & 0.007 & 2.0 & $(1.2-3.1)$ \\
\hline \multicolumn{7}{|l|}{ Confirmed* } \\
\hline 12 months & $73(54)$ & 48 (35) & 19 & 0.002 & 2.0 & $(1.3-3.6)$ \\
\hline
\end{tabular}

Note: $\mathrm{OR}=$ odds ratio, $\mathrm{Cl}=$ confidence interval.

* Patients who reported being abstinent at 12 months were asked to provide the name and phone number of a friend or relative to confirm their tobacco status. The research assistant called the friend of family member and asked if the patient had smoked or used tobacco in the last 7 days.

Table 4: Smoking abstinence 12 months after receipt of a minimal or intensive intervention for smoking cessation among patients admitted to hospital for acute myocardial infarction or coronary artery bypass grafting

\begin{tabular}{|c|c|c|c|c|c|c|}
\hline \multirow[b]{2}{*}{ Abstinence at $12 \mathrm{mo}$} & \multicolumn{2}{|c|}{$\begin{array}{l}\text { Intensive } \\
\text { intervention }\end{array}$} & \multicolumn{2}{|c|}{$\begin{array}{c}\text { Minimal } \\
\text { intervention }\end{array}$} & \multicolumn{2}{|c|}{ Total } \\
\hline & $\mathrm{n} / \mathrm{N}$ & $\%$ & $\mathrm{n} / \mathrm{N}$ & $\%$ & $\mathrm{n} / \mathrm{N}$ & $\%$ \\
\hline \multicolumn{7}{|l|}{ Pharmacotherapy*t } \\
\hline Used & $22 / 40$ & 55 & $9 / 40$ & 22 & $31 / 80$ & 39 \\
\hline Not used & $58 / 76$ & 76 & $47 / 78$ & 60 & $105 / 154$ & 68 \\
\hline Total & $80 / 116$ & 69 & $56 / 118$ & 48 & & \\
\hline \multicolumn{7}{|c|}{ Reason for admissionf } \\
\hline CABG & $30 / 42$ & 71 & $20 / 46$ & 43 & $50 / 88$ & 57 \\
\hline Acute MI & $47 / 93$ & 50 & $34 / 91$ & 37 & $81 / 184$ & 44 \\
\hline Total & $77 / 135$ & 57 & $54 / 137$ & 39 & & \\
\hline
\end{tabular}

Note: $\mathrm{CABG}=$ coronary artery bypass graft, $\mathrm{MI}=$ myocardial infarction.

*Data about the use of pharmacotherapy data were missing for 19 patients in each group; these patients were omitted from this analysis.

†Abstinence rates for pharmacotherapy are 7-day point-prevalence confirmed by proxy.

$\ddagger$ Abstinence rates by reason for admission are 12 -month continuous abstinence.
The rates of confirmed long-term abstinence observed in this trial are among the highest rates reported in cardiac popuhospital stay is more effective than a stepped-care approach that provides intensive counselling only after a patient has relapsed. ${ }^{30}$ By significantly increasing abstinence among cardiac patients, inpatient programs for smoking cessation have the potential to produce sizeable reductions in cardiac vents ${ }^{1,3,4,6,7}$ and hospital costs. ${ }^{31-34}$

In our study, slightly less than half of the identified risk of disease and the importance of quitting, as well as encourage patients to at least try to quit or move them closer to contemplating quitting. The minimal intervention (advice and pamphlets) could also be delivered to these patients as a noninteractive intervention, although resources would need to be taken into consideration.

Given that the primary aim of our trial was to establish the efficacy of the intervention, some exclusion criteria were necessary; this limits the generalizability of the findings. Most notably, cardiac patients with substance abuse or psychiatric comorbidities, or both, were excluded. These patients often require services beyond those offered by a general smoking-cessation program and beyond what the counsellors are trained to deliver. It is difficult to design cessation programs to take into account various cognitive and social deficits. ${ }^{35}$ Among psychiatric patients, smoking cessation may increase the levels of some psychiatric medications in the blood, exacerbate symptoms and result in problematic adverse effects such as anxiety and depression; ${ }^{36-38}$ the latter is an independent risk factor for heart disease. ${ }^{39}$

Fifteen years ago, routine smokingcessation interventions for cardiac patients in hospital were deemed an "idea whose time has come," ${ }^{40}$ but the interventions have not been widely adopted. The current trial contributes to the international evidence base and provides support to suggest that future research and practice should focus on dissemination of intensive interventions for smoking cessation into standard hospital practice for cardiac patients. The potential contributions to health and health care costs are substantial. 
This article has been peer reviewed.

Competing interests: Patricia Smith received travel assistance from Pfizer to attend the Global Healthcare Alliance for Treatment of Tobacco Dependence in November 2008. Pfizer manufactures a nicotine-replacement product. None declared for Ellen Burgess.

Contributors: Both Patricia Smith and Ellen Burgess contributed to the conception and design of the study. Patricia Smith designed the data collection tools, oversaw the fidelity of data collection for the CONSORT diagram and data entry, and was responsible for the data analysis and interpretation. She also drafted the article and revised the various iterations. Ellen Burgess was responsible for project management and fidelity of intervention implementation, data collection, interpretation of the data and revisions of the draft manuscript and its iterations. Both authors gave final approval of the version to be published.

Acknowledgements: We thank C. Barr Taylor MD, Robert F. DeBusk MD and Nancy Houston Miller RN BSN at the Stanford Cardiac Rehabilitation Program, Stanford University School of Medicine for sharing the intervention protocols and materials, and Bruce Weaver MA for his help with the analyses.

Funding: This research was supported with funding by the Calgary Health Region Health Promotion Fund, Aventis Canada, Merck Frosst Canada and Pfizer Canada.

\section{REFERENCES}

1. Van Spall HGC, Chong A, Tu JV. Inpatient smoking-cessation counseling and allcause mortality in patients with acute myocardial infarction. Am Heart J 2007;154 213-20.

2. Public Health Agency of Canada. Leading causes of death and hospitalization in Canada. Ottawa: The Agency; 2008. Available:www.phac-aspc.gc.ca/publicat/lcdpcd97/index-eng.php (accessed 2009 May 15).

3. Critchley J, Capewell S. Smoking cessation for the secondary prevention of coronary heart disease [review]. Cochrane Database Syst Rev 2004;(1):CD003041.

4. van Domburg RT, Meeter K, van Berkel DF, et al. Smoking cessation reduces mortality after coronary artery bypass surgery: a 20 -year follow-up study. $J A m$ Coll Cardiol 2000;36:878-83.

5. Goldman L, Garber AM, Grover SA, et al. Task force 6. Cost-effectiveness of assessment and management of risk factors. J Am Coll Cardiol 1996;27:964-1030.

6. Voors AA, van Brussel BL, Plokker HW, et al. Smoking and cardiac events after venous coronary bypass surgery: a 15-year follow-up study. Circulation 1996;93 $42-7$

7. Galan KM, Deligonul U, Kern MJ, et al. Increased frequency of restenosis in patients continuing to smoke cigarettes after percutaneous transluminal coronary angioplasty. Am J Cardiol 1988;61:260-3

8. Barth J, Critchley J, Bengel J. Efficacy of psychosocial interventions for smoking cessation in patients with coronary heart disease: a systematic review and metaanalysis. Ann Behav Med 2006;32:10-20.

9. Smith PM, Taylor CB. Implementing an inpatient smoking cessation program. London (UK): Psychology Press; 2006.

10. Taylor CB, Houston Miller N, Killen JD, et al. Smoking cessation after acute myocardial infarction: effects of a nurse-managed intervention. Ann Intern Med 1990; 113:118-23.

11. DeBusk RF, Houston Miller N, Superko R, et al. A case management system for coronary risk factor modification following acute myocardial infarction. Ann Intern Med 1994;120:721-9.

12. Smith PM, Reilly KR, Houston Miller N, et al. Application of a nurse-managed inpatient smoking cessation program. Nicotine Tob Res 2002;4:211-22.

13. Marlatt GA, Gordon JR, editors. Relapse prevention: maintenance strategies in the treatment of addictive behaviors. New York (NY): Guilford Press; 1985.

14. Baer JS, Holt CS, Lichtenstein E. Self-efficacy and smoking reexamined: construct validity and clinical utility. J Consult Clin Psychol 1986;54:846-52.

15. Houston Miller N, Taylor CB. Human Kinetics: Current issues in cardiac rehabili- tation series. Lifestyle management for patients with coronary heart disease: monograph number 2. Champaign (IL): Human Kinetics; 1995.

16. Center for Disease Control and Prevention. Classifications of diseases and functioning \& disability. Hyattsville (MD): National Center for Health Statistics; 2008. Available: www.cdc.gov/nchs/icd9.htm\#RTF (accessed 2009 May 1).

17. Killen JD, Fortmann SP. Role of nicotine dependence in smoking relapse: results from a prospective study using population-based recruitment methodology. Int J Behav Med 1994;1:320-34

18. Pechacek TF. A randomized trial for smoking cessation. In: 1987 proceedings of the sixth world conference on smoking and health; 1987 Nov 9-12; Tokyo. New York (NY): Excerpta Medica; 1988. p. 241-3.

19. Ossip-Klein DJ, Bigelow G, Parker SR, et al. Classification and assessment of smoking behavior. Health Psychol 1986; (Suppl 5):3-11.

20. Patrick DL, Cheadle A, Thompson DC, et al. The validity of self-reported smoking: a review and meta-analysis. Am J Public Health 1994;84:1086-93.

21. Glasgow RE, Mullooly JP, Vogt TM, et al. Biochemical validation of smoking status: pros, cons, and data from four low-intensity intervention trials. Addict Behav 1993;18:511-27.

22. Hyland A, Cummings KM, Lynn WR, et al. Effect of proxy-reported smoking status on population estimates of smoking prevalence. Am J Epidemiol 1997;145:746-51.

23. Patten CA, Martin JE, Filter KJ, et al. Utility and accuracy of collateral reports of smoking status among 256 abstinent alcoholic smokers treated for smoking cessation. Addict Behav 2002;27:687-96.

24. Roberts C, Torgerson DJ. Understanding controlled trials: baseline imbalance in randomised controlled trials. BMJ 1999;319:185.

25. Berger VW. A review of methods for ensuring the comparability of comparison groups in randomized clinical trials. Rev Recent Clin Trials 2006;1:81-6.

26. Trowman R, Dumville JC, Torgerson DJ, et al. The impact of trial baseline imbalances should be considered in systematic reviews: a methodological case study. $J$ Clin Epidemiol 2007;60:1229-33.

27. Babyak MA. What you see may not be what you get: A brief, nontechnical introduction to overfitting in regression-type models. Psychosom Med 2004;66:411-21.

28. Houston Miller N, Smith PM, DeBusk RF, et al. Smoking cessation in hospitalized patients. Results of a randomized trial. Arch Intern Med 1997;157:409-15.

29. Tobacco Control Program. Canadian tobacco use monitory survey (CTUMS) 2007. Smoking prevalence, Canada, 1999-2007. Ottawa (ON): Health Canada; 2007. Available: www.hc-sc.gc.ca/hl-vs/tobac-tabac/research-recherche/stat/ctums -esutc 2007-eng.php (accessed 2009 May 1).

30. Reid R, Pipe A, Higginson L, et al. Stepped care approach to smoking cessation in patients hospitalized for coronary artery disease. J Cardiopulm Rehabil 2003;23:176-82.

31. Hurley SF. Short-term impact of smoking cessation on myocardial infarction and stroke hospitalizations and costs in Australia. Med J Aust 2005;183:13-7.

32. Lightwood JM, Glantz SA. Short-term economic and health benefits of smoking cessation: myocardial infarction and stroke. Circulation 1997;96:1089-96.

33. Naidoo B, Stevens W, McPherson K. Modelling the short term consequences of smoking cessation in England on the hospitalization rates for acute myocardial infarction and stroke. Tob Control 2000;9:397-400.

34. Wagner EH, Curry SJ, Grothaus L, et al. The impact of smoking and quitting on health care use. Arch Intern Med 1995;155:1789-95.

35. Esterberg ML, Compton MT. Smoking behavior in persons with a schizophreniaspectrum disorder: a qualitative investigation of the transtheoretical model. Soc Sci Med 2005;61:293-303.

36. Dalack GW, Meador-Woodruff JH. Smoking, smoking withdrawal and schizophrenia: case reports and a review of the literature. Schizophr Res 1996;22:133-41.

37. Hughes JR. Possible effects of smoke-free inpatient units on psychiatric diagnosis and treatment. J Clin Psychiatry 1993;54:109-14.

38. Lyon ER. A review of the effects of nicotine on schizophrenia and antipsychotic medications. Psychiatr Serv 1999:50:1346-50.

39. Frasure-Smith N, Lesperance F. Recent evidence linking coronary heart disease and depression. Can J Psychiatry 2006;51:730-7.

40. Orleans CT, Ockene JK. Routine hospital-based quit-smoking treatment for the postmyocardial infarction patient: an idea whose time has come. J Am Coll Cardiol $1993 ; 22: 1703-5$

Correspondence to: Dr. Patricia Smith, Northern Ontario School of Medicine, 955 Oliver Rd., Thunder Bay ON P7B 5E1;

fax 807 766-7362; patricia.smith@normed.ca 